\title{
ART in Prevention of Mother-to-Child Transmission of HIV
}

\author{
Abhilasha Gupta $^{1} \cdot$ Aruna Verma $^{1} \cdot$ Monika Kashyap $^{1}$ [D $\cdot$ Priti Gautam $^{1}$ \\ Received: 22 January 2019 / Accepted: 9 August 2019 / Published online: 3 September 2019 \\ (c) Federation of Obstetric \& Gynecological Societies of India 2019
}

\begin{abstract}
Aim To evaluate the efficacy and safety of ART in prevention of mother-to-child transmission of HIV.

Methods All pregnant females who were tested and found positive for HIV from April 2015 to March 2017 were included in this study and started on TLE regimen (Tenofovir $300 \mathrm{mg}$, Lamivudine $300 \mathrm{mg}$, Efavirenz $600 \mathrm{mg}$ ). After delivery these newborns were given syrup Nevirapine $2 \mathrm{mg} / \mathrm{kg}$ for 6 weeks of life if mother was started on ART before 12 weeks of gestation and was continued upto 12 weeks if mother was started on ART later than 12 weeks of gestation. Infants were tested with PCR and Rapid test for HIV was done at 6 weeks, 6 months, 12 months, and 18 months of life.

Result Out of 66 HIV-positive mothers (26 diagnosed in our institute and 40 referred patients), 53 delivered in our hospital. Out of these 53 deliveries, 3 were stillbirth, so 50 babies were registered. Out of 50 registered babies, 2 babies died in follow-up (one at the age of 12 months due to malnutrition and other at the age of 4 months due to diarrhea). Five babies were referred to nearby ART centers. So, we followed 43 babies out of which two were found to be positive for HIV (transmission rate of HIV was $4.6 \%$ ).

Conclusion The risk of transmission of HIV from mother-to-child had declined with the use of combination ART, and the emergence of drug resistance was reduced. The ART used during pregnancy appears to be well tolerated and safe.
\end{abstract}

Keywords ART $\cdot$ PPTCT $\cdot$ TLE regimen $\cdot$ Nevirapine

\section{Introduction}

According to WHO, there were approximately 35 million people worldwide living with HIV/AIDS in 2013, of these 3.2 million were children (less than 15 years old). Though India has a low prevalence of HIV $0.27 \%$ in adults and $6.54 \%$ in children less than 15 years of age, yet in terms of individuals infected, India is home to the third largest number of people living with HIV in the world by virtue

Abhilasha Gupta is a Professor and Head in Department of Obstetrics and Gynaecology at LLRM Medical College, Meerut, U.P., India. Aruna Verma is an Associate Professor in Department of Obstetrics and Gynaecology at LLRM Medical College, Meerut, U.P., India. Monika Kashyap is an Ex. Assistant Professor in Department of Obstetrics and Gynaecology at LLRM Medical College, Meerut, U.P., India. Priti Gautam is a Junior Resident in Department of Obstetrics and Gynaecology at LLRM Medical College, Meerut, U.P., India.

Monika Kashyap

drmonika2k2@gmail.com

1 Department of Obstetrics and Gynaecology, LLRM Medical College, Meerut, U.P., India of its 1.2 billion populations. Nearly $5 \%$ of infections are attributable to parent-to-child transmission [1]. It is the second commonest mode of transmission of HIV [first being sexual transmission].

Women account for around one million of people living with HIV. In the absence of any intervention, an estimated cohort of 13,000 infected babies will be born annually (transmission rate 20-45\%) [2].

So, to reduce the burden of the disease by cutting down the transmission from parent to child in year 2015, WHO recommended initiation of antiretroviral therapy for all HIVinfected pregnant women regardless of CD4 cell count and to continue ART lifelong [3]. Infants born to HIV-infected mothers should also receive post-exposure antiretroviral prophylaxis.

The recommended first-line ART regimen is TLE, i.e., Tenofovir $300 \mathrm{mg}$, Lamivudine $300 \mathrm{mg}$, Efavirenz $600 \mathrm{mg}$ combination once daily in pregnant and breast-feeding women (it is same as recommended in non-pregnant adults). TLE regimen is the first line because of less side effects and once daily dosing schedule, thus increased chances of 
adherence to treatment and reduced risk of development of resistance [4].

Early testing of antenatal mothers, administration of ART, lifelong continuation, institutional delivery, counseling on infant feeding and ART to infant, effective family planning and reproductive health services and linkage to long-term HIV care are critical for prevention of PTCT of HIV. By all these means, we can achieve the goal of HIV transmission from parent to child to zero.

\section{Aims and Objectives}

- To evaluate

- The efficacy of TLE regimen in prevention of PTCT.

- To assess the safety of TLE Regimen in mother and baby.

\section{Materials and Methods}

In this study, we have included all the HIV-positive pregnant women who had delivered at LLRM Medical College and SVBP Hospital, Meerut from April 2015 to March 2017.

\section{Study Design}

Prospective observational study.

All pregnant women who came to our hospital for routine antenatal checkup were booked and thorough history with complete general, systemic and obstetrical examination was done. All routine ANC tests (hemoglobin, VDRL, urine routine and microscopy, OGTT with $75 \mathrm{~g}$ glucose, HIV, HbsAg, $\mathrm{HCV}$ ) were advised and repeated accordingly with proper antenatal care and follow-ups.

The cases who were found to be HIV reactive were confirmed by rapid immunodot test (total three cards). Other investigations like CD4 count, liver function tests were also done. Referred HIV reactive cases from nearby centers were also included in this study.

All patients were counseled in PPTCT in department of obstetrics and gynecology and started on TLE combination regimen by ART Center (HIV Department) in our hospital [Tenofovir $300 \mathrm{mg}$, Lamivudine $300 \mathrm{mg}$, Efavirenz $600 \mathrm{mg}$ ] on registration and continued throughout pregnancy, postpartum and lifelong thereafter.

After delivery all infants were registered and serial screening was done for newborns (by PCR and rapid test for HIV at 6 weeks 6 months, 12 months and 18 months of life) with post-exposure prophylaxis in form of syrup nevirapine $2 \mathrm{mg} / \mathrm{kg}$ which was continued for 6 weeks if mother was started on ART within 12 weeks of gestation and was continued upto 12 weeks if mother had started ART after 12 weeks of gestation.

Mother was counseled and advised for choice of alternative feed or breast-feed and contraceptive advice was given.

\section{Results}

In our study, total 7836 antenatal low risk women were tested for HIV in antenatal clinic from April 2015 to March 2017. Out of these 7836 women, 26 were diagnosed as HIV reactive (incidence in ANC was $0.33 \%$ ), and 40 patients were referred from other hospitals, so total 66 patients were enrolled. Total 5768 patients delivered in our institute out of these 53 were HIV positive. The incidence of HIV in delivered patients was $0.91 \%$ in our hospital because majority of patients were referred from nearby hospitals and districts.

Following observations were made:

\section{Demographic Parameters of HIV-Positive Mothers at the Time of Registration}

The mean age of HIV reactive women in our study was 26 years with majority of women belonging to age group 24-28 years. In terms of parity out of 66 patients, 27 women were primipara, 22 were nullipara, 15 were multipara and
Table 1 Demographic parameters of HIV reactive mothers at the time of registration

\begin{tabular}{lllll}
\hline Demographic parameters $(N-66)$ & & & \\
\hline Age (in years) & $20-24$ years & $25-29$ years & $30-34$ years & $35-40$ years \\
& 28 & 25 & 11 & 2 \\
Parity & $\begin{array}{l}\text { Nullipara (no prior } \\
\text { child birth) }\end{array}$ & Primipara (1 child birth) & $\begin{array}{c}\text { Multipara }(\geq 2 \\
\text { child birth })\end{array}$ & $\begin{array}{c}\text { Grand multipara } \\
\text { ( } \geq 4 \text { child } \\
\text { birth })\end{array}$ \\
& 22 & 27 & 15 & 2 \\
Gestation at diag- & $<12$ weeks & $12-23$ weeks & $24-35$ weeks & $>36$ weeks \\
nosis (in weeks) & 18 & 18 & 23 & 7 \\
\hline
\end{tabular}


Table 2 CD4 count of HIV-positive mothers at the time of registration

\begin{tabular}{lllll}
\hline CD4 count & $>500$ & $351-500$ & $251-350$ & $<250$ \\
$N(53)$ & 21 & 19 & 7 & 6 \\
\hline
\end{tabular}

2 patients were grand multipara. In our study, 18 women were diagnosed as HIV reactive and TLE was started before 12 weeks and 48 women were found to be HIV reactive after 12 weeks of gestation and treatment was started. All women were compliant and took TLE regime regularly (Table 1).

\section{CD4 Count of HIV-Positive Mothers at the Time of Registration}

In our study, 40 patients had CD 4 count $>350$ and 13 patients had CD4 count $<350$ (Table 2).

\section{Birth Weight of Infants and Gestation at Delivery of HIV-Positive Mothers}

The average weight of infants delivered was $2.6 \mathrm{~kg}$, and the mean age of gestation at delivery was 38 weeks (Table 3 ).

In total 53 deliveries, 35 (66\%) were delivered by cesarean section and 18 (44\%) by vaginal delivery. Cesarean section were done for obstetric indications only. Out of these 53 deliveries, 3 were stillbirth and 2 died in the infantile period (one at the age of 12 months due to malnutrition and other at the age of 4 months due to diarrhea). Since, these women hailed from various districts and shifted to their native places 5 babies were transferred to nearby ART centers. So we followed 43 infants.

Out of these 43 infants, 28 babies were breast-fed and 15 received alternate feeds ( 9 babies received formula feed and 6 babies received animal milk).
In these 43 infants, 41 were negative for HIV and 2 tested positive for HIV during follow-ups (transmission rate was $4.65 \%$ and efficacy of TLE $95.35 \%$ ) (Table 4).

\section{Discussion}

In 2011 , WHO estimated that only $46 \%$ of HIV-infected pregnant women in resource limited settings received antiretroviral regimens for the prevention of PTCT. The Joint United Nations program on HIV/AIDS reported that coverage of antiretroviral programs for prevention of PTCT increased from 36 to $80 \%$ in 2015 among their 21 priority countries [5].

According to HIV sentinel surveillance (HSS) 2014-2015, the overall prevalence among antenatal clinic attendees, continue to be approximately $0.29 \%$ (90\% CI $0.28-0.31$ ) in our country [6]. In our study, the incidence was $0.33 \%$ in antenatal clinic.

As we discussed before that in absence of any antiretroviral therapy, the risk of vertical transmission is approximately 15-45\%. Use of single-dose nevirapine to mother and syrup nevirapine to newborn has shown reduction in transmission to $10 \%$ or less. Combination ART followed by post-exposure prophylaxis to the newborn as recommended by WHO in 2013 has potential to further reduce transmission to less than $5 \%$ in breast-feeding population [2]. In our study, the transmission rate is $4.65 \%$.

Dr. S. Sumithra et al. followed 74 babies born to HIV reactive mothers receiving TLE in their study. Out of these, 5 tested positive for HIV and 69 were negative. The transmission rate of HIV was $6.7 \%$ [7].

According to the latest guidelines of ACOG given in 2018 stabilized and ongoing research has shown that treatment of HIV-infected pregnant women with combined ART can achieve a $1-2 \%$ or lower risk of mother-to-child transmission

Table 3 Birth weight of infants and gestation at delivery of HIV reactive mothers

\begin{tabular}{llllll}
\hline Birth weight at delivery (in kg) & $3-3.5 \mathrm{~kg}$ & $2.5-3 \mathrm{~kg}$ & $2-2.5 \mathrm{~kg}$ & $1.5-2.0 \mathrm{~kg}$ & $1.0-1.5 \mathrm{~kg}$ \\
$N(53)$ & 14 & 20 & 15 & 3 & 1 \\
Gestation at the time of delivery (in weeks) & $25-27.6$ weeks & $28-30.6$ weeks & $31-33.6$ weeks & $34-36.6$ weeks & $37-39.6$ weeks \\
$N(53)$ & 1 & 1 & 1 & 3 & $43-42$ weeks \\
\hline
\end{tabular}

Table 4 Characteristics of HIV-positive baby $(N-2)$

\begin{tabular}{lllllll}
\hline Parity & $\begin{array}{l}\text { Gestation at start of } \\
\text { TLE (weeks) }\end{array}$ & CD4 count & $\begin{array}{l}\text { Gestation at } \\
\text { delivery }\end{array}$ & Mode of delivery & Feeding practices & Positive at age \\
\hline Nullipara & 37 & 530 & 38 & Cesarean section & Formula feeding & 6 weeks \\
Primipara & 8 & 371 & 40 & Cesarean section & Breast-feeding & 12 months \\
\hline
\end{tabular}


if maternal viral load of 1000 copies/ml or less can be sustained, independent of the route of delivery or duration of ruptured membranes before delivery [8].

NACO also do not recommend Cesarean sections for prevention of PTCT. Particularly, where women are taking ART for their own health, C-section should be performed for obstetric indications only [2]. In our study, we did cesarean in these patients for obstetric indications only.

Combination ART is well tolerated except for few GI side effects, hyperglycemia, elevated liver transaminases. In our study, we did not encounter any major side effect in patients for which discontinuation of the drugs was needed. So this regime is quiet convenient because of once daily dosing and without much side effects.

Most studies from developing countries have suggested an increased risk of preterm births, stillbirths, intrauterine growth restriction and death of infants born with HIV-infected women with more advanced disease [9] which can only be prevented by active interventions like antiretroviral drugs and other measures. The use of antiretroviral drugs in pregnancy has generally been found to be safe in trials till date and the benefits for preventing fatal illness in mothers and reduction in PTCT been judged to outweigh the potential adverse effects. Currently, recommended regime TLE has been used extensively during pregnancy and appear to be well tolerated and safe. However, further studies regarding potential risk of birth defects and end organ toxicities in women are necessary to assure short and long-term safety [10,11].

The use of combination ART avoids the problem of low efficacy and emergence of higher rates of viral resistance associated with the use of single-dose nevirapine and zidovudine [12].

In year 2009, WHO released new recommendations on infant feeding by HIV-positive mothers, according to which babies of HIV-positive mothers can have benefit of breastfeeding with very little risk of becoming infected with HIV. Research had shown that exclusive breast-feeding in the first six months of an infant's life is associated with a three- to fourfold decreased risk of HIV transmission compared to infants who were breast-fed [13].

In our study, we counseled parents for feeding methods and their risks and we emphasized regarding avoidance of any kind of mixed feeding at all. Out of 43 babies, 28 babies were breast-fed (65\%) and 15 were on alternative feeds (35\%) and no baby received mixed feeding.

Previously it was considered that LSCS prevents the mother to child of HIV. In our study, we found that both HIV-positive newborns were delivered by cesarean section. So, mode of delivery does not change the transmission rate.

Out of the 2 infants who tested reactive for HIV, mother of one baby was diagnosed HIV positive at 37 weeks of gestation and she delivered at 38 weeks, so even by giving
ART her viral load may have not reduced to sufficiently low levels. This baby was formula fed and found reactive at very early age of 6 weeks.

The mother of second baby was diagnosed and started ART at 8 weeks of gestation, she delivered at 38 weeks. Baby received nevirapine after delivery and was breastfed. This baby was found reactive at 12 months of age. So even after receiving post-exposure prophylaxis, this baby may become reactive through breast-feeding, as there is no method by which we can reduce the risk of transmission to zero percent till date by any treatment.

\section{Conclusion}

- New pediatric HIV infections from PTCT remain a substantial health burden in our country. With improved access to antiretroviral agents and improved care delivery systems, the goal of virtual elimination of HIV can be achieved.

- The tide of emerging drug resistance is reduced with combination ART compared to single-dose nevirapine.

- Nevertheless, successful prevention programs must also include other measures like rapid HIV testing, monitoring and support for antiretroviral adherence and toxicity, counseling on infant feeding, effective family planning and reproductive health services and linkage to long-term HIV care.

Funding Antiretroviral treatment to the patients was provided by ART Center of our institute which is funded by UPSACS (U.P. state AIDS control society) as per NACO guidelines.

\section{Compliance with Ethical Standards}

Conflict of interest The authors declare that they have no conflict of interest.

Ethical Statement The authors that all procedures performed in this study involving human participants were in accordance with the ethical standards of the institutional research committee and with the 1964 Helsinki Declaration and its later amendments or comparable ethical standards.

Informed Consent An informed consent was obtained from all the individual participants in the study.

\section{References}

1. UNICEF India. HIV/AIDS. Available from latest stories. http:// www.unicef.in/story/1123/HIV-AIDS. Accessed Dec 2017. 
2. NACO: Updated Guidelines for PPTCT of HIV using multidrug antiretroviral regimen in India, December 2013. http://naco.gov. in/upload/NACP\%20\%20IV/18022014\%20BSD/National_guidl ines_for_PPTCT.pdf. Accessed Sept 2017.

3. World Health Organization. Guideline on when to start antiretroviral therapy and on pre-exposure prophylaxis for HIV, Sept 2015. http://apps.who.int/iris/bitstream/10665/186275/1/97892 41509565_eng.pdf?ua=1. Accessed 30 Sept 2015.

4. WHO consolidated guidelines on the use of antiretroviral drugs for treating and preventing HIV infection, recommendations for a public health approach, June 2013. http://www.who.int/hiv/pub/ guidelines/arv2013/download/en/. Accessed Dec 2017.

5. World Health Organization. On the fast track to an AIDS-free generation. Geneva, Switzerland. 2016. http://emtct-iatt.org/wpcontent/uploads/2016/06/globalplan2016_en.pdf. Accessed 20 June 2016.

6. NACO Annual Report 2016-17. http://naco.gov.in/documents/ annual-reports.pdf. Accessed Aug 2018.

7. Sumithra S, Manonmani R. Efficacy of TLE regimen in prevention of mother to child transmission of HIV. IOSR J Dent Med Sci. 2017;16(2):36-8.

8. Committee on Obstetric Practice; HIV Expert Work Group. ACOG committee opinion number-751: Labor and delivery management of women with HIV virus infection. American College of Obstetricians and Gynecologists. Obstet Gynaecol. 2018;132:e131-7.

9. James DK, Steer PJ, Weiner CP, Gonik B. High risk pregnancy, management options. 4th ed. Amsterdam: Elsevier; 1994. p. 480-1.

10. Zash R, Souda S, Chen JY, et al. Reassuring birth outcomes with Tenofovir/Emtricitabine/Efavirenz used for prevention of motherto-child transmission of HIV in Botswana. J Acquir Immune Defic Syndr. 2016;71:428.

11. Malaba T, Phillips T, Petro G, et al. Timing of ART initiation in pregnancy and birth outcomes in South African women. In: Conference on retroviruses and opportunistic infection, 22-25 Feb 2016, Boston, MA. Abstract 799.
12. Fowler MG, Qin M, Fiscus SA, et al. Benefits and risks of antiretroviral therapy for perinatal HIV prevention. N Engl J Med. 2016;375:1726-37.

13. WHO. Breast is always best even for HIV positive, Nov 2009. http://www.who.int/bulletin/volumes/88/1/10-030110.pdf. Accessed July 2018.

Publisher's Note Springer Nature remains neutral with regard to jurisdictional claims in published maps and institutional affiliations.

\section{About the Author}

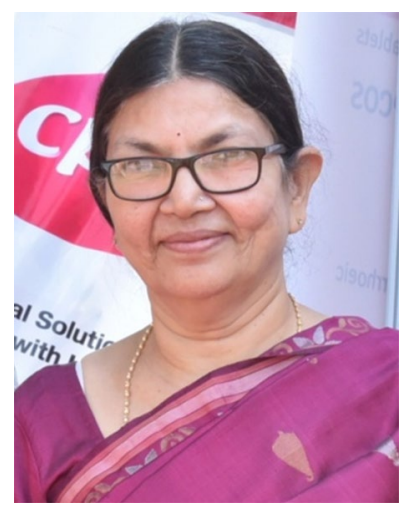

Dr. Abhilasha Gupta has done her MBBS, MD, DGO, from King George Medical College Lucknow. She has 35 years of teaching experience, heading the Department of Obstetrics and Gynecology at LLRM Medical College, Meerut for 11 years. She is member of editorial board of journal of UPCOG. She has published and presented many papers, lectures and orations in national and regional conferences. She is member of editorial board of journal of UPCOG and also contributed chapters in many books. Her special interests are high risk pregnancy and infertility. 